\title{
Attitudes to smoking and smoking habits among hospital staff
}

\author{
S F Hussain, S Tjeder-Burton, I A Campbell, P D O Davies
}

\begin{abstract}
Background Health professionals should take an active role against smoking, so it is relevant to have information on their smoking habits and their attitudes towards smoking, especially with a view to identifying and offering help to those smokers who wish to stop. Staff in Llandough Hospital were surveyed to determine their smoking habits and attitudes, and the findings were compared with those of a similar survey at Llandough in 1987.

Methods In October 1991 a questionnaire was sent to each member of staff employed half time or more requesting data on age, sex, department, smoking habit, attitudes to smoking in various areas of the hospital, and attitudes to access to smoking rest rooms for patients, staff, and visitors. Smokers were asked whether they would like to join a "quit smoking" group. Nonresponders were sent a reminder four weeks later and all replies returned by 31 December 1991 were analysed.
\end{abstract}

Results The response rate was $82 \%$; of the respondents, $65 \%$ were non-smokers, $15 \%$ ex-smokers, and $20 \%$ current smokers. The prevalence of current smokers was $5 \%$ among doctors, $20 \%$ among nurses, $18 \%$ among administrative and clerical staff, and $40-42 \%$ among domestics, catering, and portering staff. Thirty eight per cent of responders wished smoking to be completely forbidden in all areas of the hospital and $90 \%$ in certain areas such as wards, offices, cafeteria, and laboratories. Nearly half wanted smoking to be allowed in rest rooms and over $60 \%$ wanted a 24 hour facility for smoking for staff, $56 \%$ for patients, and $44 \%$ for visitors. Only $39 \%$ of smokers wished to join a "quit smoking" support group. In comparison with the 1987 survey, the response rate in this study was higher $(82 \% v 70 \%)$, the proportion of non-smokers had increased (65\% v 59\%), and more smokers wanted help (39\% $v$ $26 \%$ ). Fewer wanted 24 hour access to smoking areas for staff and for visitors.

Conclusion This hospital should capitalise on these changes of attitude among staff and proceed more rapidly with the implementation of policies to further reduce smoking among staff, visitors, and patients. As a first step a smoking cessation counsellor has been appointed.

(Thorax 1993;48:174-175)
Smoking related diseases account annually for more than 110000 premature deaths and cost NHS hospital services more than $£ 400$ million per year. Health professionals should take an active role against smoking, so it is relevant to have information on the smoking habits of health professionals themselves and their attitudes towards smoking. It is also important to identify and offer help to those smokers who wish to give it up.

A survey of all paid staff in Llandough Hospital was carried out to determine their smoking habits and their attitudes towards smoking. Llandough Hospital is one of three hospitals in Cardiff which function as teaching hospitals as well as district general hospitals, and contains the specialist departments of thoracic medicine and thoracic surgery. The results were compared with those of a similar survey performed at Llandough about five years ago.

\section{Methods}

All staff employed by the hospital on 1 October 1991 were identified. Those employed less than half time were excluded from the survey. A questionnaire was sent to each member of the staff in the last week of October 1991.

Information requested included age, sex, smoking habit, and department in which employed. Staff were asked if smoking should be permitted in various areas of the hospital (such as wards, offices, and cafeteria), and whether there should be 24 hour access to smoking rest rooms for patients, staff, and visitors. Smokers were asked whether they would like to join a "quit smoking" support group. An addressed envelope was provided to facilitate return. Each questionnaire was coded so that non-respondents were identified and a reminder sent to them four weeks later. Replies returned by the end of December 1991 were analysed. Differences were tested for statistical significance by the $\chi^{2}$ test.

\section{Results}

One thousand three hundred and forty four employees were identified, of whom 37 were on long term leave and were not sent questionnaires. Of the 1307 possible responders, $1069(82 \%)$ completed and returned the questionnaires. Overall $20 \%$ of staff were current smokers, $15 \%$ ex-smokers and $65 \%$ nonsmokers (table). Current smoking was lowest among doctors $(5 \%)$, highest in members of the domestic, catering and portering staff 
Comparison of response rate and smoking habit by department of present survey with 1987 survey in the same hospital

\begin{tabular}{|c|c|c|c|c|c|c|c|c|c|c|c|c|}
\hline \multirow[b]{3}{*}{ Department } & \multirow{2}{*}{\multicolumn{2}{|c|}{$\begin{array}{l}\text { Total No. } \\
\text { of staff }\end{array}$}} & \multirow{2}{*}{\multicolumn{2}{|c|}{$\begin{array}{l}\text { Total No. } \\
\text { Responders }\end{array}$}} & \multirow{2}{*}{\multicolumn{2}{|c|}{$\begin{array}{l}\text { Response } \\
\text { rate (\%) }\end{array}$}} & \multicolumn{6}{|c|}{ Smoking habit (\%) } \\
\hline & & & & & & & \multicolumn{2}{|c|}{ Non-smokers } & \multicolumn{2}{|c|}{ Ex-smokers } & \multicolumn{2}{|c|}{ Current smokers } \\
\hline & 1991 & 1987 & 1991 & 1987 & 1991 & 1987 & 1991 & 1987 & 1991 & 1987 & 1991 & 1987 \\
\hline Nursing & 588 & 361 & 491 & 272 & 83 & 75 & 67 & 61 & 13 & 17 & 20 & 21 \\
\hline Doctors & 104 & 94 & 84 & 68 & 80 & 72 & 78 & 71 & 17 & 26 & 5 & 3 \\
\hline Admin/clerical & 223 & 110 & 201 & 90 & 90 & 82 & 70 & 61 & 12 & 26 & 18 & 18 \\
\hline Scientific & 151 & 163 & 129 & 125 & 85 & 77 & 65 & 65 & 19 & 23 & 16 & 11 \\
\hline Domestic & 82 & 106 & 59 & 50 & 72 & 47 & 46 & 32 & 13 & 12 & 41 & 57 \\
\hline Catering & 68 & 60 & 38 & 17 & 56 & 28 & 47 & 47 & 13 & 18 & 40 & 35 \\
\hline Portering & 37 & 34 & 31 & 25 & 84 & 74 & 29 & 44 & 29 & 12 & 42 & 44 \\
\hline Works & 54 & 21 & 36 & 16 & 67 & 76 & 56 & 31 & 33 & 50 & 11 & 19 \\
\hline Total & 1307 & 949 & 1069 & 663 & 82 & 70 & 65 & 59 & 15 & 19 & 20 & 23 \\
\hline
\end{tabular}

(40-42\%), and $10-20 \%$ among others.

Female responders numbered 864 (81\%) and male 205 (19\%). Among the females 567 (66\%) were non-smokers, 121 (14\%) exsmokers and $176(20 \%)$ current smokers. The corresponding figures for males were $\mathbf{1 2 2}$ $(60 \%), 42(20 \%)$ and $41(20 \%)$ respectively. The prevalence of smoking was $24 \%$ in those aged 30 years or under, and $19 \%$ in those aged 31 years and over $(p=0 \cdot 08)$. Of the responders, $404(38 \%)$ believed that smoking should be forbidden in all areas of the hospital. Nearly $90 \%$ wanted smoking to be completely forbidden in wards, toilets, offices, cafeteria, halls, changing rooms, and laboratories. Nearly half $(48 \%)$ wanted smoking to be allowed in the rest rooms and under a third $(28 \%)$ in the coffee room. Only four responders believed that smoking should be allowed in all areas of the hospital. The proportions who believed that there should be a 24 hour facility for staff to smoke were $62 \%$, for patients $56 \%$, and for visitors $44 \%$. Of the 217 current smokers, 85 (39\%) wished to join a "quit smoking" support group, 122 $(56 \%)$ refused help and 10 (5\%) were unsure about it.

In comparison with a similar survey carried out in this hospital in $1987,{ }^{1}$ the response rate was higher in this study $(82 \% v 70 \%, \mathrm{p}<$ $0.001)$, more responders were non-smokers $(65 \% v 59 \%, \mathrm{p}=0.02)$, but the drop in smokers from $23 \%$ to $20 \%$ was not significant. The proportion of smokers accepting the offer of help rose from $26 \%$ to $39 \%$ (p < 0.05). Fewer employees wanted 24 hour access to smoking areas for staff $(62 \% v 70 \%$, $\mathrm{p}<0.002)$ and for visitors $(44 \% v 59 \%, \mathrm{p}<$ 0.001 ), but just over $50 \%$ in each study wanted patients to have 24 hour access to smoking areas.

\section{Discussion}

During an illness smokers may be more likely to give up the habit. For advice given to patients to be credible, health care professionals have an obligation not to smoke themselves. It is important to identify smokers among hospital staff in order to give them advice and to offer support to those who wish to stop. The overall response rate of $82 \%$ in our study reflects the willingness of nearly all hospital staff to cooperate in this survey. Administrative staff $(90 \%$ response rate) more than doubled between the two surveys, a fact which might account for the higher overall response rate in this survey. The prevalence of non-smoking among this responsive group was higher than in any other group except for doctors (table).

Smoking was rare among doctors (5\%) but was still appreciable among the nurses $(20 \%)$ and remained high among the domestic, catering, and portering staff (40\%). The lowest response rate was from catering staff $(56 \%)$, where smoking prevalence was high $(40 \%)$, but in domestic and portering staff with a similarly high smoking prevalence the response rates were $72 \%$ and $84 \%$ respectively.

This study identified a group of current smokers in the hospital who were willing to give up smoking and expressed their desire to receive help. Encouragement and support are being provided to this motivated group by a smoking cessation counsellor funded by Llandough Hospital. Nearly $60 \%$ of current smokers among the responders did not wish to stop. This may reflect their unawareness of the dangers of smoking to themselves, their family, and those around them. They may previously have tried to give up and failed, or may be worried about weight gain. Whatever the reason, this group of health professionals with a strong compulsion to continue to smoke should be provided with more information about the risks of smoking and the benefits of giving it up. They should be encouraged by colleagues who have successfully stopped smoking. Meanwhile, those who do not smoke should continue to demand a smoke free environment at work.

We wish to thank $\mathrm{Dr} R$ Watura, registrar, Department of Radiology, University Hospital of Wales, Cardiff, and Dr R Richards, senior registrar, General and Chest Medicine, Llandough Hospital, Cardiff, for their help and advice and Mrs Elizabeth Lyons for secretarial help. We also thank the staff at Llandough Hospital for their cooperation.

1 Davies PDO, Rajan K. Attitudes to smoking and smoking habit among staff of a hospital. Thorax 1989;44:378-81. 